\title{
Knowledge, Attitude, and Behavior Level of Women of Reproductive Age toward Calcium Intake
}

\author{
Kartika Ratna Dewi, ${ }^{1}$ Eva M Hidayat, ${ }^{2}$ Anita Rachmawati ${ }^{3}$ \\ ${ }^{1}$ Faculty of Medicine Universitas Padjadjaran, ${ }^{2}$ Department of Basic Medicine Faculty of \\ Medicine, Universitas Padjadjaran, ${ }^{3}$ Department of Obstetric and Gynecology Faculty of Medicine \\ Universitas Padjadjaran/Dr. Hasan Sadikin General Hospital Bandung, Indonesia
}

\begin{abstract}
Background: Women have a higher risk of developing osteoporosis compared to men. Calcium intake is one of the determinant factor which can be modified to prevent osteoporosis. Knowledge, attitude and behaviour are important factors to fulfill the needs of calcium intake. This study aimed to describe knowledge, attitude, and behavior toward calcium intake of woman of reproductive age.

Methods: This descriptive study recruited 100 women (aged 20-30 years) in Jatinangor, West Java and was conducted from September to November 2014. Knowledge and attitude measurements used a validated questionnaire consisting of 10 and 9 closed questions respectively. Behavioral aspect was assessed using semi-quantitative Food Frequency Questionnaire (FFQ). Knowledge was classified as high, moderate, and low based on questionnaire scoring results, $>75 \%, 60-75 \%$, and $<60 \%$ respectively. Attitude was categorized in two: positive and negative. Behaviour category used Recommended Dietary Allowances (RDA) as the cutoff point. If the daily calcium intake is below the RDA it is categorized less and if the daily calcium intake equals to or exceeds the RDA it is categorized sufficient. The collected data were presented in frequency tabulation and percentage.
\end{abstract}

Results: The majority of subjects showed low to moderate level of knowledge toward calcium intake, $66 \%$ of subjects showed negative attitude towards calcium intake, and $98 \%$ showed calcium intake below the RDA.

Conclusions: Subjects of this study have low to moderate level of knowledge, negative attitude toward calcium intake, and low level of behavior toward calcium intake.

Keywords: Attitude, behavior, calcium intake, knowledge

\section{Introduction}

The bone has a remodeling process, that is the process of solving existing bones which will be replaced by new bone components, and this process occurs throughout life. ${ }^{1}$ Bones will reach peak bone mass at around the age of 30 years. $^{2}$ Then, starting from 30 to 40 years old, there will be an increase of releasing bone minerals that exceeds its formation, mainly in women. ${ }^{1,3}$ When peak bone density is optimally reached, it can prevent and reduce an osteoporosis risk. ${ }^{3}$

The risk of osteoporosis is still high in Indonesia, 2 in 5 Indonesian population are at risk for osteoporosis. ${ }^{4}$ Furthermore, osteoporosis is called a silent disease because of a decrease in bone density without causing symptoms until a fracture occurs. ${ }^{5}$ Although it is called as a silent disease, osteoporosis is a disease that can be prevented. ${ }^{6}$ In the prevention of osteoporosis, the peak bone mass needs to be considered as a determinant of bone health, thus optimizing on bone mineral accretion is important. ${ }^{7}$

The main factors that affect bone density are the calcium intake in childhood, adolescence and early adulthood. ${ }^{8}$ However, the average calcium intake of the Indonesian society is still low, for example $254 \mathrm{mg} /$ day (only a quarter of the international standard, that is 1000 to $1200 \mathrm{mg} /$ day for adults). ${ }^{4}$

One of the important factors related to the level of calcium intake in women is knowledge. ${ }^{9}$ Moreover, the primary domain of human behavior in the form of operations consists of knowledge, attitude, and actions. ${ }^{10}$ Therefore, this study aimed to describe the level of knowledge, attitude and behavior of women of reproductive age toward calcium intake to prevent osteoporosis.

Correspondence: Kartika Ratna Dewi, Faculty of Medicine, Universitas Padjadjaran, Jalan Raya Bandung-Sumedang Km.21, Jatinangor, Sumedang, Indonesia, Email: kartika_rtndewi@yahoo.com 


\section{Methods}

This study used a quantitative descriptive method with a cross-sectional design and was conducted during the period of September to November 2014 in Jatinangor, Sumedang, West Java province. The data collection process was approved by the Health Research Ethics Committee of Faculty of Medicine Universitas Padjadjaran and the Government of Sumedang District.

The study population was all women of reproductive age in Jatinangor subdistrict. Sample of this study was women of reproductive age between 20 to 30 years who live in the Cipacing, Hegarmanah, and Cikeruh villages, Jatinangor. The purposive sampling technique was used for selecting the villages. Villages which had the highest number of women of reproductive age were selected. Then, the sample was collected by visiting and tracing the villages to meet women of reproductive age who met the appropriate inclusion criteria. The minimum sample in this study was calculated by a descriptive categorical formula, and the result was 97 people. Those included in the study were women of reproductive age between 20 to 30 years, willing to be the respondent and ever heard about calcium. While excluded from the sample were women of reproductive age who did not complete the questionnaire.

The variables of this study were knowledge, attitude, and behavior of women of reproductive age toward calcium intake to prevent osteoporosis. Knowledge and attitude masurements used validated questionnaires consisting of 10 and 9 closed questions respectively. First, it was the predefined variables that we identified and constructed questions of the appropriate variables. After the questionnaire was constructed, it was tested to 30 respondents and processed for validity and reliability. Meanwhile, the behavioral aspect was assessed using the semi-quantitative Food Frequency Questionnaire (FFQ). The FFQ questionnaire started with a list of foods containing calcium, and then continued with a pre-elimination study to adapt to the types of food around the sample. Data was clarified to determine what foods would be incorporated or removed from the questionnaire. Prior to its use, the questionnaire was consulted to a Nutritionist. Furthermore, the Guttman scale was used to query knowledge. The Likert scale with 4 scales was used to measure attitude. All obtained data were incorporated into Microsoft Excel 2007. Knowledge was classified as high, moderate, or low based on questionnaire scoring results, $>75 \%, 60-75 \%$, and $<60 \%$ respectively. Attitude was categorized using

\section{Table 1 Characteristics of Respondent}

\begin{tabular}{lcc}
\hline Characteristics of respondent & Frequency (n=100) & Percentage (\%) \\
\hline Level of education & 1 & $1 \%$ \\
Elementary school & 30 & $30 \%$ \\
Junior high school & 53 & $53 \%$ \\
Senior high school & 16 & $16 \%$ \\
College & & \\
Occupation & 67 & $67 \%$ \\
Housewife & 4 & $4 \%$ \\
Teacher & 3 & $3 \%$ \\
Seller & 8 & $8 \%$ \\
Labor & 10 & $10 \%$ \\
Employee of company & 6 & $6 \%$ \\
Collegian & 2 & $2 \%$ \\
Others & & \\
Income per month & 27 & $27 \%$ \\
Less than regional minimum wage & 73 & $73 \%$ \\
Same or more than regional minimum wage & & \\
\hline
\end{tabular}


Table 2 Level of Knowlegde about Calcium Intake to Prevent Osteoporosis

\begin{tabular}{|c|c|c|}
\hline Knowlegde & Frequency (n) & Percentage $(\%)$ \\
\hline High & 28 & $28 \%$ \\
\hline Moderate & 40 & $40 \%$ \\
\hline Low & 32 & $32 \%$ \\
\hline Total & 100 & $100 \%$ \\
\hline
\end{tabular}

the median attitude resulting in two categories: positive and negative. The behavior category of calcium intake used the Recommended Dietary Allowances (RDA) as the cut-off point, so if the amount of daily calcium intake was below the RDA it was categorized less and if the amount of daily calcium intake equals to or exceeds the RDA it was categorized sufficient.

\section{Results}

After the distribution of 107 questionnaires to reproductive-aged women in Cipacing, Hegarmanah, and Cikeruh, there were 100 respondents included in this study. Out of 100 respondents, most of them had completed senior high school (53\%), worked as housewife $(67 \%)$, and had a monthly income which was similar to or more than the regional minimum wage in Sumedang District (73\%).

Furthermore,most of the respondents had a moderate level of knowledge about calcium intake (40\%), negative attitude toward calcium intake (66\%), and less than RDA for behavior toward calcium intake (98\%) (Table 2, 3, and 4). Based on a normality test, data from this study was normally distributed with the daily calcium intake of $410.1955 \pm 206.385 \mathrm{mg}$.

\section{Discussions}

This study discovered that the majority of the respondents had a low to moderate level of knowledge about calcium intake. This result was consistent with a study conducted by Von Hurst and Wham ${ }^{11}$ on 622 women aged 20-49 years in Auckland, New Zealand. The study measured the level of knowledge about osteoporosis risk factors, including calcium intake. ${ }^{11}$ Additionally, Rafraf et al. ${ }^{12}$ found the same results in 399 fertile women in Tabriz, Iran which was in line with a study conducted in Egypt. ${ }^{13}$ The level of knowledge was defined as moderate, and might be caused by the knowledge of osteoporosis that have not been internalized among women, including educated women in this study. ${ }^{12}$ There were some differences according to the study conducted by Wahba, et al. ${ }^{14}$ in Cairo in 494 women aged 16-24. The study stated that the respondent's knowledge about the intake of calcium to prevent osteoporosis is still very poor and limited. The difference in results may be due to the respondent's age difference. The age of respondents in Cairo ${ }^{14}$ was younger than those in this study. An increase in age will be followed by an increase in knowledge

Table 3 Attitude toward Calcium Intake to Prevent Osteoporosis

\begin{tabular}{lccc}
\hline \multicolumn{1}{c}{ Attitude } & Median & Frequency (n) & Percentage (\%) \\
\hline Positive & $>75$ & 34 & $34 \%$ \\
Negative & $<75$ & 66 & $66 \%$ \\
Total & & 100 & $100 \%$ \\
\hline
\end{tabular}

Table 4 Behavior toward Calcium Intake to Prevent Osteoporosis

\begin{tabular}{lcc}
\hline \multicolumn{1}{c}{ Behavior } & Frequency (n) & Percentage (\%) \\
\hline Fulfill RDA & 2 & $2 \%$ \\
Less than RDA & 98 & $98 \%$ \\
Total & 100 & $100 \%$ \\
\hline
\end{tabular}


about osteoporosis. Apparently, the increased age of a woman, specifically which is closer to menopause, would raise the concern of women to the risk of osteoporosis. ${ }^{11}$

In this study, the majority of respondents, as many as 66 people (66\%) had negative attitudes. The result was contrary to the study conducted by Hussein, et al. ${ }^{13}$ in Egypt involving 400 women aged 18-28 years and Sriring, et al. ${ }^{15}$ in Thailand involving 1475 adults aged 20 years and above. Both studies indicated that overall respondents have positive attitudes. The difference in the results of these studies may be due to differences in the components of attitude of the respondents in this study compared to other studies, both of emotion involved (such as experience) as well as the confidence of the self respondent. ${ }^{10}$

The result of calcium intake in this study showed that the average calcium intake per day of the respondents in Cipacing, Hegarmanah, and Cikeruh was 410.1955(206.385) mg/ day. This result implied that most of the respondents did not meet the RDA $(1100 \mathrm{mg} /$ day for people aged 19-29 years and 1000 $\mathrm{mg}$ /day for people aged 30 years). ${ }^{16}$ Ninety eight percent of the respondents had a daily calcium intake below the RDA. This result was in line with a study by Rafraf, et al. ${ }^{12}$ The result of calcium intake in the study indicated that most women of reproductive age do not fulfill the recommended daily calcium needs. The average daily calcium intake of the respondents is $689.08(393.15) \mathrm{mg} /$ day and most of the women who were interviewed $(50.7 \%)$ consumed the daily calcium needs less than $60 \%$ of the recommended amount..$^{2}$ The study in Cairo, Egypt ${ }^{14}$ also showed a similar result, with an average calcium intake of the respondents $470(311.5) \mathrm{mg} /$ day and $86.5 \%$ of respondents consumed calcium below the recommended amount. Another study conducted in Taipei, Taiwan ${ }^{9}$ also showed that the average calcium intake in young women do not fulfill the needs, that is equal to 454 $\mathrm{mg} /$ day. The average calcium intake of the Indonesian society is still low, i.e. $254 \mathrm{mg} /$ day. $^{4}$ The average of calcium intake in this study was much lower than the RDA. It might be caused by the lack of knowledge about the types of food source containing calcium, especially aside from milk and other dairy products, such as vegetables, and fish. ${ }^{11}$ There were $51 \%$ respondents who provided the right answer in the knowledge part about food sources of calcium.Therefore, it could be inferred that only half of the respondents were aware of the calcium food source aside from milk and dairy products. In fact, there are other food sources containing high calcium, such as anchovy and rebon. ${ }^{4}$ Besides low calcium intake can be also caused by the lack of knowledge of the respondent about the RDA of calcium. ${ }^{11}$ Based on the answers regarding the need for daily calcium intake, $90 \%$ of respondents in this study chosed the wrong answer.

On further review of the frequency, amount and type of food consumed by the respondents, it seemed that the frequency of milk consumption and other dairy products, like milk, cheese, yogurt, ice cream, was still fairly low. Out of 100 respondents, 9 respondents consumed milk every day. In fact, milk and other dairy products have a very high calcium content. ${ }^{3}$ The respondent, who had the highest daily calcium intake, can be detected from the higher frequency in milk consumption, i.e. three times a day plus the consumption of cereals and processed soybean, such as tofu and tempe, as well as green vegetables, such as beans, spinach, and water spinach. It seemed that there was no intake of milk and dairy products in the low calcium intake group. Other foods known as a source of calcium are cassava leaves, beans, tofu, but the content of calcium inside them still is less than those in milk. $^{3}$

This study revealed that the knowledge level of the majority of respondents was categorized as moderate. Knowledge, thoughts, beliefs, and emotions play an important role in determining the whole attitude. ${ }^{10}$ The respondent's behavior belongs to less category from RDA, and this relates to the statement that the attitude is not necessarily manifested in action because action needs other factors, among others, the facilities and infrastucture. ${ }^{10}$ In this study, the less action can be caused by the unavailability of sufficient calcium food in each household. In the study conducted in Tabriz, Iran, ${ }^{12}$ it was stated that the adequate knowledge is often not accompanied by the application of lifesyle.

The limitation in this study was the use of the non-probability or non-random sampling technique, while the technique that really could represent the population was a random technique, so, the samples of this study were less representative to the population. During the interview process, it was possible that the respondent forgot to mention the type and amount of food consumed, and there was still a possibility that the calculation of calcium intake was less meticulous. However, due to the limited time and experience in conducting this study, the study method was considered to 
be the most likely to be carried out.

Based on the data processing result, it can be concluded that the majority of respondents have low to moderate knowledge about calcium intake to prevent osteoporosis in Jatinangor sub-district. The majority of respondents have a negative attitude toward calcium intake to prevent osteoporosis in Jatinangor sub-district. Almost all respondents have less behavior in fulfilling calcium intake toward preventing osteoporosis in Jatinangor sub-district.

\section{References}

1. Brandi ML. Microarchitecture, the key to bone quality. Rheumatology (Oxford). 2009;48(Suppl4):iv3-8.

2. Sasson H CC. Achievement of peak bone mass in women is critically dependent on adolescent calcium intake. OA Sports Med. 2013;1(2):16.

3. Whitney E, Rolfes SR. Understanding Nutrition. 12th ed. Wadsworth: Cengage Learning; 2011.

4. Menteri Kesehatan Republik Indonesia. Kepmenkes No.1142/MENKES/SK/ XII/2008 tentang Pedoman pengendalian osteoporosis. Jakarta: Kementerian Kesehatan Republik Indonesia; 2008.

5. Agrawal V, Gupta D. Recent update on osteoporosis. Int J Med Sci Public Health. 2013;2(2):164-8.

6. Puttapitakpong $\mathrm{P}$ Chaikittisilpa $\mathrm{S}$, Panyakhamlerd K, Nimnuan C, Jaisamrarn $\mathrm{U}$, Taechakraichana $\mathrm{N}$. Inter-correlation of knowledge, attitude, and osteoporosis preventive behaviors in women around the age of peak bone mass. BMC Womens Health. 2014;14(1):35.
7. Baxter-Jones ADG, Faulkner RA, Forwood MR, Mirwald RL, Bailey DA. Bone mineral accrual from 8 to 30 years of age: An estimation of peak bone mass. J Bone Miner Res. 2011;26(8):1729-39.

8. Poslušná K, Matějová H, Březková V. Risk factors of osteoporosis knowledge and practices among adolescent females. School and Health. 2008;21(3):211-20.

9. Chang SF. A cross-sectional survey of calcium intake in relation to knowledge of osteoporosis and beliefs in young adult women. Int J Nurs Pract. 2006;12(1):21-7.

10. Soekidjo Notoatmodjo. Ilmu perilaku kesehatan. Jakarta: Rineka Cipta; 2010.

11. Von Hurst PR, Wham CA. Attitudes and knowledge about osteoporosis risk prevention: a survey of New Zealand women. Public Health Nutr. 2007;10(7):747-53.

12. Rafraf M, Bazyun B, Afsharnia $F$. Osteoporosis-related life habits and knowledge about osteoporosis among women in Tabriz, Iran. IMJ. 2009;8(2):1720.

13. Hussein RAEH, Ashqan BS, Jamalallail $\mathrm{RH}$, Alafeef AS. Knowledge, attitude, and behavior of young women towards dietary calcium intake. Life Science Journal. 2013;10(3):2491-6

14. Wahba SA, El-Shaheed AA, Tawheed MS, Mekkawy AA, Arrafa AM. Osteoporosis knowledge, beliefs, and behaviors among egyption female students. JASMR. 2010;5(2):173-80.

15. Sriring P, Krass I, Kanjanarach T. Calcium consumption for osteoporosis prevention: knowledge, attitudes and behavior in the northeastern region, Thailand. J Med Assoc Thai. 2014;97(2):232-40. 